\title{
trabalnonecessário
}

issn: $1808-799 \mathrm{X}$

ano 7 - número 9 - 2009

\section{CEFET CELSO SUCKOW E ALGUMAS TRANSFORMAÇÕES HISTÓRICAS NA FORMAÇÃO PROFISSIONAL ${ }^{1}$}

\author{
Marisa Brandão - marisabrandao1@gmail.com
}

\begin{abstract}
Resumo:
Este trabalho ressalta aspectos da história do CEFET- Celso Suckow da Fonseca no contexto de transformações da formação profissional no Brasil em dois períodos. Dos anos de 1910 aos de 1940: a mudança de uma formação que desenvolve valores morais junto às classes populares, com um ensino baseado na 'arte do ofício', para uma formação que atende às demandas de qualificação exigidas pela incipiente indústria. Dos anos de 1960 aos de 1970: o processo no âmbito das políticas do MEC, onde se misturam e se confundem concepções de "ensino profissionalizante", "ensino superior", "educação tecnológica", dentre outras. Nesse processo surge um novo tipo de ensino superior, em um novo tipo de instituição - os CEFETs. O texto relaciona as mudanças institucionais com as mudanças mais gerais das políticas públicas voltadas para a formação profissional, posto estarem atreladas aos caminhos econômicos que o país traça a partir do embate de interesses em disputa.
\end{abstract}

Palavras-chave: formação profissional, educação profissional, ensino superior, educação tecnológica.

\section{Abstract:}

This article highlights aspects of the history of CEFET (Federal Centre of Technology Education, Rio de Janeiro, named after Prof. Celso Suckow da Fonseca) in the context of the occupational training transformations in Brazil in two periods. From 1910s to the 1940s: a change from training that developed moral values and education among the lower classes based on learning a trade or craft, to one that matches the skill and qualification requirements of incipient industry. From 1960s to1970s: a process promoted by the Ministry of Education's policies, in which conceptions of "career/occupational education", "further/higher education", "technological/technical education", among others, are merged. It is in this process that a new type of higher education arises, in a new kind of institution - the CEFET. The institutional changes are related with the more general public policy shifts aimed at occupational training, in turn, linked to the country's economic trajectory and the various interests at stake.

Keywords: occupational training, occupational education, further/higher education, technological/technical education. 


\section{trabalhonecessário}

issn: $1808-799 \mathrm{X}$

ano 7 - número 9 - 2009

\section{1- Apresentação}

Inicialmente, ressaltamos que este trabalho não tem a intenção de esgotar a história do CEFET Celso Suckow da Fonseca, do Rio de Janeiro; pretendemos simplesmente ressaltar alguns aspectos de dois períodos distintos dessa Instituição e, ao mesmo tempo, relacionar as mudanças institucionais com as mudanças mais gerais das políticas públicas, definidas pelo poder executivo do governo federal, voltadas para a formação profissional. Mesmo que nesse trabalho não seja explicitado, defendemos que estas políticas públicas estão diretamente relacionadas aos caminhos econômicos que o país vem traçando a partir do embate de interesses em disputa.

Este texto tem como base, para o período que vai dos anos de 1910/1920 até os anos de 1940, minha dissertação de mestrado (Brandão, 1997). Nela tratamos das transformações ocorridas na formação profissional no Brasil, quando vai deixando de ter, por um lado, a função de buscar para os "filhos dos desfavorecidos da fortuna" o desenvolvimento de "hábitos de trabalho profícuo, que os afastará da ociosidade, escola do vício e do crime" (como determinava o já muito comentado Decreto 7566, de 23 de setembro de 1909). Por outro lado, mudando também sua concepção, de uma formação com base na arte para uma formação com base na ciência. Nesse período, podemos perceber que o desenvolvimento econômico e industrial do país leva à necessidade de uma força de trabalho com certo nível de qualificação profissional, modificando assim a orientação das políticas públicas neste campo.

Em relação ao período que vai dos anos de 1960 aos anos de 1970, tomamos como base estudos realizados para tese de doutorado (Brandão, 2009). Quanto a esse período, o que procuramos destacar é a transformação de uma instituição voltada para a formação profissional em nível secundário (ou médio) em uma instituição que passa a incluir um determinado tipo de ensino superior. Essa trajetória, que tornará a própria Instituição específica, começa com os Cursos de 


\section{trabalhonecessário}

issn: $1808-799 \mathrm{X}$

ano 7 - número 9 - 2009

Engenharia de Operação, nos anos de 1960, culminando, nos anos de 1970, com a transformação destes em Engenharia Industrial e, ao mesmo tempo, com a criação e formalização de um outro tipo de ensino superior, os Cursos Superiores de Tecnologia. Em termos institucionais, essas transformações levam à criação dos primeiros Centros Federais de Educação Tecnológica, os CEFETs.

Esperamos que esse trabalho possa contribuir para as reflexões e ações do presente, tanto no que se refere ao próprio CEFET-CSF/RJ, quanto no que se refere às questões mais amplas das políticas públicas definidas no âmbito do poder executivo.

\section{2- Da arte do ofício à ciência da indústria, ou, da Escola Normal de Artes e Ofícios Wenceslau Brás à Escola Técnica Federal Celso Suckow da Fonseca}

Nas primeiras décadas da república brasileira, ainda no início do século XX, a educação nacional tinha como característica marcante, seguindo ainda uma herança do período colonial e imperial, a organização de instituições profissionalizantes de caráter essencialmente assistencialista, sem uma preocupação efetiva de formação de uma força de trabalho qualificada. Ao mesmo tempo, coerente com a descentralização do poder do Estado que então predominava, não existia uma política educacional em nível nacional e não tínhamos regulamentações para todo o país. No entanto, na prática, tinha-se um destino educacional traçado para as classes dominantes - a escola secundária e a superior - e outro para os trabalhadores - a escola primária e a profissional. É neste contexto que, em 1909, assistimos à criação da rede federal de Escolas de Aprendizes Artífices, voltada para a formação profissional, então com base artesanal e também assistencialista - formalmente estabelecida para atender aos desfavorecidos da fortuna -, não ultrapassando o nível primário de educação. Essa rede é a origem da hoje legalmente instituída 'Rede Federal de Educação Profissional, Científica e Tecnológica', da qual fazem parte os recém criados 'Institutos Federais de Educação, Ciência e Tecnologia' (IFETs), a Universidade 


\section{trabalnonecessário}

issn: $1808-799 X$

ano 7 - número 9 - 2009

Tecnológica Federal do Paraná (UTF-PR), os Centros Federais de Educação Tecnológica Celso Suckow da Fonseca (CEFET-RJ) e de Minas Gerais (CEFETMG), assim como algumas Escolas Técnicas vinculadas a Universidades Federais (Lei ํㅜ11.892, de 29 de dezembro de 2008).

O CEFET do Rio de Janeiro, no entanto, tem sua origem em um projeto inicialmente pensado pela prefeitura do então Distrito Federal. Através de decreto municipal, foi criada, em agosto de 1917, a Escola Normal de Artes e Ofícios Wenceslau Brás, voltada

para a instrução e preparo de professores, mestres e contra-mestres dos vários Institutos e escolas profissionais do Distrito Federal, assim como de professores de trabalhos manuais para as escolas primárias" (artigo $1^{\circ}$ do Decreto 1.800, de 11 de agosto de 1817).

Essa Escola é considerada a primeira no Brasil com o objetivo de formar professores voltados especialmente para o ensino profissional.

Em acordo com o governo federal, a prefeitura consegue que the seja cedido o prédio da Rua General Canabarro, ${ }^{\circ}{ }^{338}$, para a instalação da Escola e, no dia 9 de novembro de 1918, tem-se sua inauguração com a presença do próprio presidente da República, Wenceslau Brás, do prefeito, do diretor nomeado para a escola, Coryntho da Fonseca, dentre outros. Porém, apesar de inaugurada oficialmente nesta data, suas atividades só serão iniciadas em agosto de 1919, ainda sem o funcionamento das suas oficinas, o que se daria no ano seguinte.

Segundo Celso Suckow da Fonseca (1986), quando Paulo de Frontin assumiu a Prefeitura do Distrito Federal, resolveu fechar a escola por achá-la demasiadamente dispendiosa. Ao mesmo tempo, o governo federal buscava alguma solução para a falta de professores e mestres que assumissem o ensino na rede de Escolas de Aprendizes Artífices, fundada em 1909. Desta forma, ainda em julho de 1919, começaram os entendimentos entre a União e a Prefeitura a fim de transferir a Escola Wenceslau Brás para o âmbito federal. E, após decretos que autorizavam a 


\section{trabalhonecessário}

issn: $1808-799 \mathrm{X}$

ano 7 - número 9 - 2009

transferência2, em 27 de novembro do mesmo ano, firmou-se o acordo final, passando a escola ao governo federal, ficando subordinada ao Ministério da Agricultura, Indústria e Comércio, passando a fazer parte, então, da rede de Escolas de Aprendizes Artífices.

Tendo sido criada com objetivos específicos, desde o início a Wenceslau Brás tinha características que a distinguiam desta Rede e que foram mantidas pelo acordo de transferência para a União. A seus alunos era exigido, para ingresso, o curso primário, e a Escola não dava "preferência aos desfavorecidos da fortuna"; a maioria de seus professores tinha nível superior. O objetivo institucional era formar profissionais mais próximos da moderna indústria que começava a se implantar no país. Estes profissionais, por sua vez, formariam operários adequados a esta nova realidade - a de uma indústria que se desenvolvia já a partir da introdução de algum conhecimento científico na base do processo produtivo, portanto começando a se distanciar da base subjetiva da arte.

Mas nem sempre as intenções, sejam das leis, sejam daqueles que na prática dão a direção e o sentido a um projeto, conseguem ser realizadas. Observase, a partir de documentos que nos mostram o cotidiano da Wenceslau Brás, que muitas vezes a realidade dos cursos, das oficinas e o que nelas era ensinado nos remete "de volta" à manufatura, ou até mesmo ao artesanato. De uma forma geral, o levantamento dos documentos referentes à Wenceslau Brás que foram preservados e se encontravam à época desta pesquisa (1994/1997) no Arquivo Geral do CEFET-RJ, nos levam a defender que havia uma predominância dos cursos da "seção de trabalhos femininos", sobressaindo-se os trabalhos manuais, domésticos, artísticos, de acordo com a noção de "trabalho feminino" então existente. As próprias fotografias de exposições em que a Escola esteve presente, apresentando os trabalhos realizados em suas oficinas, demonstram o fato3. 


\section{frabalhonecessário}

issn: $1808-799 \mathrm{X}$

ano 7 - número 9 - 2009

Em Boletins de Renda e Produção4 do ano de 1924, onde se declara a quantia monetária recolhida ao Tesouro Nacional "resultante da produção pelas diversas seções deste Estabelecimento", constam artigos das seções de chapéus, costuras, bordados, flores, economia doméstica e madeira, demonstrando os cursos/oficinas que sobressaíram naquele ano, ao menos em termos quantitativos. Temos ainda dados de Celso Suckow da Fonseca (1986, v.3, p.135/136) sobre matrículas e diplomados, desde o início do funcionamento da Wenceslau Brás até seu fechamento, comprovando a predominância do gênero feminino entre os alunos da Escola e, portanto, a predominância dos cursos de "formação de professores de datilografia, estenografia, modas ou economia doméstica".

llustrando os interesses econômicos e sociais mais amplos que se colocavam para o Brasil, em 1927, Graco Cardoso, então deputado, apresenta um projeto de lei5 que busca traçar "princípios orgânicos", a serem adotados nacionalmente, para o ensino que ele próprio denomina de "ensino técnico industrial". Apesar de não ter sido aprovado, o projeto de lei já apresentava a proposta de uma formação profissional escolar de nível médio, de preparação de um profissional até então inexistente no Brasil, o técnico, que estaria entre o operário e o engenheiro, pois

O ensino de artes e ofícios, como está sendo feito atualmente, se em umas escolas é insuficiente para formar operários ou artífices, em outras não é bastante para habilitar mestres ou condutores de indústrias, pois os seus cursos são, simplesmente, de categoria de contra-mestres.

E nem a tarefa de preparar mestres e condutores de indústrias cabe ao ensino industrial primário. Essa é a missão do ensino médio, ao passo que a do ensino superior industrial é formar os engenheiros das escolas politécnicas (ibid.)

Nas transformações que os diferentes órgãos do poder executivo do governo federal voltados para a gestão do "ensino profissional técnico" vão sofrendo, podemos perceber a crescente importância deste ensino. Percebemos também, por um lado, o processo de mudança na sua função - de solução para problemas 


\section{frabalhonecessário}

issn: $1808-799 \mathrm{X}$

ano 7 - número 9 - 2009

urbanos à formação de uma mão-de-obra que se tornava então necessária ao desenvolvimento capitalista do país. E, por outro lado, o processo de mudança na sua concepção - de formação com base na arte, voltada para o artesanato, à formação com base na ciência, voltada para a indústria. Neste sentido, através de decreto de julho de 1934, tem-se a transformação da 'Inspetoria de Ensino Profissional Técnico' em 'Superintendência do Ensino Industrial ${ }^{6}$, que passará a ser um órgão diretamente subordinado ao Ministro da Educação ${ }^{7}$. Este será o primeiro órgão governamental que assumirá o projeto industrial, em termos da formação profissional, de forma explícita, a começar por sua própria denominação.

No decreto de 1934 que cria este órgão e dá outras providências, podemos observar a ruptura que então se processava no ensino profissionalizante no país em termos de função e de concepção. Vejamos algumas de suas considerações:

Considerando que a evolução das indústrias nacionais impõe a adaptação do ensino indispensável à formação dos operários às exigências da técnica moderna;

Considerando que atualmente este ramo educativo está restrito, nos estabelecimentos oficiais, a uma organização que apenas atende à formação de artífices para as profissões elementares;

Considerando que a falta de operários graduados e de contra-mestres é, além de manifesta, penosamente sentida nas fábricas e nas oficinas;

Considerando que as indústrias nacionais já exigem um operariado com conhecimentos especializados e de nível superior ao do ensino primário; [...] (Decreto 24.558, de 03 de julho de 1934)

Desta forma, em 1934, observa-se modificações na concepção que se tinha para o ensino profissionalizante, já colocando as diretrizes básicas que se projetava para as Escolas de Aprendizes Artífices e para a Escola Normal de Artes e Ofícios Wenceslau Brás. Não é por acaso que neste texto legal evitou-se a referência ao nome das escolas, usando-se termos como 'escolas federais de ensino profissional técnico', 'estabelecimentos de ensino industrial', 'escolas federais de ensino industrial', 'institutos profissionais da União', 'escolas industriais', 'ensino industrial'. O projeto de escola que se tinha em mente não era mais aquela que pretendia ser 


\section{trabalnonecessário}

issn: $1808-799 \mathrm{X}$

ano 7 - número 9 - 2009

apenas uma solução moral, ou ideológica, para os problemas sociais; nem tão pouco o projeto de ensino era aquele que formaria um artesão, ciente dos 'mistérios' artísticos de seu ofício. O cenário social era outro, uma ruptura havia se operado; tratava-se de formar mão-de-obra para a indústria nacional, com "conhecimentos especializados e de nível superior ao ensino primário", com uma formação que atendesse "às exigências da técnica moderna".

Em 1937, dando continuidade a este novo projeto educacional, o Ministério da Educação e Saúde Pública passa a ter nova organização (Lei 378, de 13 de janeiro), inclusive quanto às questões relacionadas à formação profissional. Esta mesma lei transforma a Escola Wenceslau Brás (e a rede à qual a escola pertencia) em liceus que, posteriormente, começam a ser chamados de 'Liceus Industriais'.

Em setembro de 1937 a Escola Wenceslau Brás fecha suas portas para se iniciarem as obras de sua demolição, a fim de ceder lugar à materialização do novo projeto que se impunha para o ensino profissionalizante - o projeto industrial. Em 29 de agosto de 1937, o jornal Diário Carioca publicou um protesto contra a possível demolição do "notável edifício de cunho histórico, que é o palacete, outrora pertencente ao Duque de Saxe, onde vem funcionando a Escola Wenceslau Brás". Portanto, a história desta Instituição pode ser vista como a materialização do projeto de "ensino profissionalizante industrial", passando por um processo que culminará com sua demolição - simbólica e literal - para ceder lugar ao novo, que nela já havia se anunciado. O projeto para a futura Escola era grandioso, incluindo, dentre outros, não apenas a demolição de todas as construções que existiam, mas também a desapropriação de terrenos próximos, a construção de modernos edifícios e de oficinas em forma de pavilhões como os das fábricas.

Trata-se aqui de destacar um projeto e um processo histórico que vão além da própria Escola Normal de Artes e Ofícios Wenceslau Brás. Este projeto não poderia ter se concretizado na existência da Wenceslau Brás - esta, mesmo com 


\section{frabalhonecessário}

issn: $1808-799 \mathrm{X}$

ano 7 - número 9 - 2009

suas especificidades, existiu com base em uma realidade histórica, específica, da formação profissional e da própria política econômica governamental de seu tempo, portanto, dificilmente poderia deixar de ter predominância na 'arte do ofício'. Por isso, era necessário demolir, em vários sentidos, as lembranças do passado.

Este projeto - da educação nacional e não apenas da Escola Wenceslau Brás - foi amadurecendo até se concretizar, em termos legais, na chamada Lei Orgânica do Ensino Industrial (de fato, Decreto 4.073, de 30 de janeiro de 1942) e, em termos materiais, nas 'Escolas Técnicas' e nas 'Escolas Industriais' do governo federal de uma forma geral. Assim, quando a antiga Escola Normal de Artes e Ofícios Wenceslau Brás reabre suas portas, em 1942 (em 1944, o presidente Getúlio Vargas fará uma inauguração oficial), era, de fato, uma outra escola. Não era mais aquela escola normal, de artes e ofícios, também não era um Liceu - era a 'Escola Técnica Nacional' (ETN), uma escola voltada para o ensino industrial. Segundo a Lei Orgânica - e condizente com o discurso de harmonia entre as classes sociais, típico do capitalismo - o objetivo era atender tanto aos interesses dos trabalhadores, quanto aos interesses dos empresários industriais.

Apesar da organização do ensino industrial em nível técnico (isto é, secundário), naquele momento o curso ainda não permitia o acesso irrestrito ao ensino superior. A seus concluintes apenas era possível o "ingresso em estabelecimento de ensino superior, para matrícula em curso diretamente relacionado com o curso técnico concluído, verificada a satisfação das condições de preparo, determinadas pela legislação competente" (Decreto 4.073/1942, art. 18, III). A "legislação competente", especificando quais os cursos do nível superior "relacionados" ao técnico, só apareceria onze anos após a Lei Orgânica, isto é, em 1953 (Lei 1.821, de 12 de março). Nesse momento, permitiu-se, em princípio, o acesso a qualquer curso superior; no entanto, devido à exigência de exames complementares ao vestibular, esta equivalência torna-se mais formal do que real. Apenas em 1961, com a Lei de Diretrizes e Bases da Educação Nacional (LDBEN, 


\section{trabalnonecessário}

issn: $1808-799 X$

ano 7 - número 9 - 2009

4.024, de 20 de dezembro) se estabelece a completa equivalência dos cursos técnicos ao secundário, para efeito de ingresso em cursos superiores.

Em 1965, a ETN passa a ser denominada 'Escola Técnica Federal da Guanabara' e, em 1967, como homenagem ao seu ex-diretor, recebe nova denominação, 'Escola Técnica Federal Celso Suckow da Fonseca' (ETF-CSF). Referência nacional quanto ao ensino profissionalizante industrial, tendo publicado importante material sobre a história deste ensino no Brasil8, "a trajetória desse engenheiro-educador está intimamente ligada à história da Escola Técnica Nacional/Federal (ETN/ETF)" (Rodrigues, 2002, p. 49). Celso Suckow dirigiu esta instituição por diversas vezes, tendo falecido em 1966, "quando viajava pelos Estados Unidos em missão profissional, a convite da Fundação Ford. Em 13 de março de 1967 (Decreto-lei 181, de 17/02/1967), a Escola Técnica Federal recebeu o nome de Escola Técnica Federal Celso Suckow da Fonseca" (Franco e Gontijo, 2002, p.253).

\section{3- De formação profissional à "educação tecnológica", ou, de Escola Técnica Federal à Centro Federal de Educação Tecnológica}

Desde os primeiros anos da década de 1960 existia a formulação - com referenciais legais - de uma política governamental de expansão do ensino superior com base em cursos de curta duração ${ }^{9}$. Essa política foi colocada em prática, inicialmente, com os cursos de Engenharia de Operação que, devido a diferentes pressões contrárias, acabou esgotando-se, mas, ao mesmo tempo, tornou-se o embrião de um projeto mais amplo, na década de 1970, visando à difusão do que, a partir de 1973, seria reconhecido como Curso Superior de Tecnologia (ou, Curso de Formação de Tecnólogos). Essa política, ainda em meados da década de 1960, começa a se configurar como uma política não-universitária, isto é, tendo como pressuposto para sua difusão a criação de instituições específicas para estes cursos. Neste sentido, a rede federal de formação profissional (isto é, as Escolas 


\section{trabalnonecessário}

issn: $1808-799 \mathrm{X}$

ano 7 - número 9 - 2009

Técnicas Federais) teve um importante papel, nas décadas de 1960 e 1970, na busca de consolidação, tanto dos cursos, quanto do projeto de instituição.

Inicialmente, algumas Universidades Católicas (PUCs), como a de São Paulo, se interessaram em implantar e difundir a engenharia de operação, porém não seriam cursos com caráter terminal, permitindo aos alunos complementarem seus estudos a fim de se tornarem "engenheiros plenos". Acontece que o modelo defendido por estas universidades em relação aos cursos de engenharia de operação entrou, em parte, em conflito com os interesses dos países do capitalismo central em relação ao Brasil. A estes interessava incentivar em nosso país cursos superiores (no sentido de que se tem acesso após a escola secundária), porém de nível intermediário, entre o nível médio e o superior propriamente dito, e visando terminalidade10. Já as Universidades Católicas - privadas - compreendiam que o tipo de aluno que possuíam - os que podiam pagar para estudar - não teria interesse em um curso que não lhes permitisse complementar a formação.

Na tentativa de modificar essa tendência, a Fundação Ford11 ofereceu ajuda em forma de consultoria técnica e bolsas de estudos, dentre outras, à PUC de São Paulo. Tendo essa instituição se negado a mudar seu modelo, os assessores da Fundação encontram receptividade na então Escola Técnica Federal da Guanabara (ETF/GB). Como resultado, em 1965, começam os acordos para um plano com o objetivo de expandir os cursos de engenharia operacional em uma escola pública de nível médio (Soares, 1983, p.226). A escolha de uma Escola Técnica Federal (ETF) pode ser explicada, em parte, porque era uma instituição que não possuía ensino superior, eliminando a possibilidade de continuidade de estudos e, portanto, eliminando a própria expectativa, neste sentido, por parte dos alunos. Por outro lado, sendo uma instituição pública de formação profissional, poderia atrair os que naquele momento a freqüentavam, isto é, os filhos da classe trabalhadora sem condições econômicas para pagar por educação. Estes, ao terem acesso a uma formação para postos de trabalho mais qualificados - mesmo que em um nível 


\section{frabalhonecessário}

issn: $1808-799 \mathrm{X}$

ano 7 - número 9 - 2009

intermediário de ensino superior -, poderiam se sentir plenamente atendidos, posto que, provavelmente, isto significaria uma elevação dos níveis escolares na família, criando a expectativa de uma possível elevação das condições econômicas.

No entanto, estabeleceu-se certa disputa entre o modelo estabelecido pelas PUCs - e encampado por outras instituições privadas - e o modelo estabelecido pela Fundação Ford em acordo com a ETF/GB. Nessa disputa, tem-se a proibição, através de Decreto12, da criação de cursos superiores em escolas de ensino médio. No entanto, poucos dias antes desse decreto, a ETF da Guanabara celebrou, em 8 de outubro de 1965, convênio com a então Escola Nacional de Engenharia da Universidade do Brasil (Universidade Federal do Rio de Janeiro) que, por sua vez, seria responsável pela emissão dos diplomas13. Segundo Góes Filho (1976, p.561976a), os cursos começaram a funcionar em março de 1966 nas especialidades de mecânica e eletrônica; no entanto, entre alguns autores existe discordância em relação a quais teriam sido as especialidades dos primeiros cursos14.

O modelo de curso superior intermediário e terminal - da Fundação Ford com apoio do governo militar - buscava garantir para o Brasil a (con)formação de profissionais adequados para operarem a tecnologia que estava sendo importada, contribuindo para a manutenção de uma política educacional brasileira onde não se projetava ampliar a capacidade de desenvolver ciência e, portanto, sua própria tecnologia. A engenheira de operação foi então definida como uma "formação profissional 'tecnológica', de nível superior", em cursos com duração de 3 anos - em oposição aos "cursos de formação profissional 'científica', que não se confundem com os primeiros por exigirem preparação científica muito mais ampla e, em conseqüência, maior duração", isto é, de 5 anos (Parecer 25/65. Grifo nosso).

Em 1967, devido às diversas pressões sociais quanto à engenharia de operação - pressões inclusive dos próprios Conselhos de representação profissional 


\section{trabalhonecessário}

issn: $1808-799 \mathrm{X}$

ano 7 - número 9 - 2009

dos engenheiros15 - o governo forma um Grupo de Trabalho (GT) para examinar estes novos cursos. Das conclusões e sugestões apresentadas por este grupo, conforme destacadas por Góes Filho (op.cit., p.56), tem-se a consideração, dentre outras, de que os cursos de engenharia de operação ministrados, em convênio, na então Escola Técnica Federal Celso Suckow da Fonseca (antiga ETF da Guanabara) vinham obtendo "resultados animadores". Ressaltamos que este GT estava examinando cursos ainda bastante recentes, pois havia apenas um ano e meio que os cursos de engenharia de operação estavam funcionando na ETF Celso Suckow. No entanto, a conclusão do GT foi a de sugerir a implantação dos cursos de engenharia de operação em diversas Escolas Técnicas Federais e, não por acaso, lembrando exemplos de instituições européias e norte-americanas. Por trás da defesa de um determinado tipo de curso superior, já se encontrava a defesa de um determinado tipo de instituição de ensino superior - uma instituição não-universitária.

Em abril de 1969, a sugestão deste Grupo já era decretada, tornando-se realidade e tendo como base a lei da reforma universitária de 1968 (Lei 5.540, de 28 de novembro de 1968). Consequentemente, a partir da experiência da ETF Celso Suckow da Fonseca, as Escolas Técnicas Federais passaram a poder solicitar autorização a fim de "organizar e manter 'cursos de curta duração', destinados a proporcionar 'formação básica de nível superior' e correspondentes às necessidades e características dos mercados de trabalho regional e nacional" (Decreto-lei 547, de 18 de abril de 1969, art.1ํ. Grifo nosso). Note-se que o decreto não se refere especificamente à engenharia de operação, mas sim a 'cursos de curta duração'. A partir de então, as ETFs passam a não depender de convênios com universidades ao solicitarem autorização para ministrarem cursos considerados de nível superior. Reforçava-se desta maneira o projeto de uma instituição de ensino superior específica, em oposição ao que é universal - uma das bases de definição da Instituição Universitária. 


\section{frabalnonecessário}

issn: $1808-799 X$

ano 7 - número 9 - 2009

Em 1971, um Projeto que havia sido desenvolvido com o apoio da Fundação Ford resultou no chamado "Acordo MEC/BIRD I" - isto é, acordo entre o Ministério da Educação e o Banco Internacional de Reconstrução e Desenvolvimento16. Esse Acordo obteve empréstimo do BIRD para o "financiamento parcial de um programa do ensino médio (profissional) e superior de curta duração (engenharia de operação), a cargo do Ministro da Educação e Cultura"17. O Acordo previa, dentre outras iniciativas, a

Construção de prédios, instalações, equipamentos de oficinas e laboratórios, bem como a formação e preparação de recursos humanos, em todos os níveis, no país e no exterior, de 6 (seis) Centros de Engenharia de Operações, juntos às Escolas Técnicas Federais de: a) Rio de Janeiro; b) São Paulo; c) Paraná; d) Minas Gerais; e) Bahia; f) Pernambuco. (apud Nascimento, ibid., p.45. Grifos nossos)

O professor Edmar de Oliveira, então diretor da ETF Celso Suckow da Fonseca, foi o primeiro a coordenar este Programa que ficou conhecido como PRODEM. Vários professores da formação profissional foram estudar nos EUA com apoio financeiro tanto daquele Projeto, quanto deste Programa. Devemos destacar que na equipe do PRODEM estavam três professores - Floriano Porto Carrero, Carlos Magno Pereira e Osvaldo Vieira Nascimento (os dois últimos da ETF-CSF/RJ) - que, segundo o próprio Osvaldo (Nascimento, op.cit., p.45), formavam "uma jovem equipe de educadores idealistas, recém chegada dos Estados Unidos onde concluíram o curso de Mestrado em Educação Técnica na Oklahoma State University enviados pelo próprio projeto". Como vemos, já naquele momento, havia a preocupação de setores do governo federal, junto a agências internacionais de financiamento, principalmente estadunidenses, em (con)formarem aqueles que iriam formular, coordenar e implantar as políticas do Estado brasileiro quanto à educação, neste caso, profissional.

Durante quase toda a década de 1970, pode-se observar a disputa de interesses em torno da engenharia de operação - seja a favor de sua manutenção, de sua modificação, ou mesmo de sua extinção. No âmbito do MEC as disputas 


\section{frabalhonecessário}

issn: $1808-799 \mathrm{X}$

ano 7 - número 9 - 2009

ocorriam através do Departamento de Assuntos Universitários (DAU) e o Departamento de Ensino Médio (DEM). O DAU defendia - na política de expansão do 'ensino superior' através de cursos de curta duração - a substituição da Engenharia de Operação pelo que passaria a ser chamado de 'Cursos de Formação de Tecnólogos' (ou, 'Cursos Superiores de Tecnologia' - CST), que teriam uma abrangência maior do que a área da engenharia. O Departamento de Ensino Médio do MEC, ao qual estavam vinculadas as Escolas Técnicas Federais (que, inclusive, cederam quadros dirigentes a este Departamento), de fato, também defendia uma política de expansão do ensino superior não-universitário. Porém, neste caso, insistiam que essa política deveria se dar através dos cursos de engenharia de operação e das próprias ETFs. Provavelmente, tal posicionamento devia-se, por um lado, ao Projeto no qual haviam investido desde 1965, resultando no PRODEM (1971) e, por outro lado, pelas estreitas ligações com as EFTs. Desta forma, podemos perceber que as disputas não se davam quanto a esta política educacional para o ensino superior, mas sim quanto a qual deveria ser o caminho para implantá-la.

Em 1975, o Conselho Federal de Educação (CFE; substituído pelo atual Conselho Nacional de Educação - CNE) aprova um parecer (CFE 1.589/75, de 8 de maio) que trata da criação dos 'Centros de Educação Tecnológica'. No parecer tem-se explícita referência ao papel que caberia a estes Centros, "uma função dissuasória, desafogando a universidade de muitos pretendentes que se contentariam com uma formação profissional curta de nível superior". Ainda não foi neste momento que o caminho para os cursos superiores de curta duração foi definido e, no decorrer das discussões sobre a engenharia de operação, neste ano de 1975, o curso estava em funcionamento não apenas na ETF Celso Suckow da Fonseca (Rio de Janeiro), mas também nas ETFs de Minas Gerais e Paraná.

No entanto, em 1976, já se falava na criação de 'Centros de Engenharia' (e não mais de Engenharia de Operação) com a verba daquele Acordo MEC/BIRD (de 


\section{frabalhonecessário}

issn: $1808-799 \mathrm{X}$

ano 7 - número 9 - 2009

1971). e, no final do ano de 1976, o CFE aprova um Parecer (CFE 4.434) extinguindo a engenharia de operação e criando a 'engenharia industrial'18. Essa seria uma 'engenharia de ligação', tendo como característica a formação de um profissional voltado para a prática - para operar e cuidar da manutenção de equipamentos, para gerenciar processos - porém, com a duração de cinco anos; pois só assim poderia ser considerado como um curso que formasse engenheiros. Em oposição, tinha-se a 'engenharia de concepção'; os engenheiros de concepção seriam "aqueles que têm a formação direcionada para o campo da pesquisa, de projetos, de investigação, da aplicação de métodos científicos, da direção, da supervisão e do ensino de engenharia" (Apud Oliveira, 2003, p.22). Ora, se observarmos bem, o que em 1976 distinguia os dois tipos de engenharia - de concepção e de ligação - eram as mesmas características que, em 1965, no parecer CFE 25, haviam distinguido o engenheiro de operação ("formação profissional tecnológica") do engenheiro graduado ("formação profissional científica"). A única diferença das características destes dois momentos era quanto à duração mínima agora, com a engenharia industrial, este tipo de formação não poderia ser curta (com 2.200 horas), passando à obrigatoriedade de, no mínimo, 3.600 horas.

No parecer 4.434/76 - em paralelo com a engenharia de concepção e a de ligação - é descrita uma terceira categoria de profissional neste campo de saber,

os tecnólogos com formação voltada para a área de engenharia, definindo-os como profissionais responsáveis pela aplicação de métodos e conhecimentos científicos e tecnológicos, combinados com habilidade manual, para a solução dos problemas relacionados à sua área de atuação. Sua atuação não se estende ao desenvolvimento de novos princípios e métodos. (Oliveira, op. cit., p.22. Grifos nossos)

Desta forma, ao mesmo tempo em que - na construção de uma solução negociada - se faz concessão à 'engenharia industrial', busca-se garantir a manutenção e consolidação de cursos superiores de curta duração - então já formalmente reconhecidos como 'tecnólogos' - na área da engenharia. 


\section{trabalnonecessário}

issn: $1808-799 X$

ano 7 - número 9 - 2009

Para Nascimento (op. cit., p.48), "a solução encontrada atendia aos desejos emanados do DAU/MEC, mas, também, preservava o ethos do ensino industrial defendido pelas Escolas Técnicas Federais, através do PRODEM"19.

Também foi em 1976 que o MEC - através de convênio com a Fundação Centro de Educação Técnica da Bahia (CETEBA), instituição estadual - conseguiu aprovar a Lei de criação do Centro de Educação Tecnológica da Bahia (CENTEC-BA)20, sendo este "o primeiro centro criado a nível federal" (Peterossi, 1980, p.78).

A idéia era, de fato, criar um "Centrão" que abrangesse desde os cursos da Escola Técnica, passando por aqueles de formação de tecnólogos (previstos para o CENTEC), até os cursos de engenharia industrial. Transcrição da ata da reunião da Diretoria da ETF-BA, de 25 de novembro de 1976, registra que

O Professor Ruy Santos Filho [então diretor da escola] fez um minucioso relato sobre os entendimentos levados a efeito nesta Capital, com a presença dos representantes do PRODEM, Cel. Arivaldo Fontes e do Sr. Guedes, Gerente de Engenharia; dos representantes do DAU e da Secretaria Geral do MEC, Dr. Ruy Vieira, e do Centro Tecnológico da Bahia, Dr. João Augusto, em relação ao Curso de Engenharia de Operações que pretendem modificar para Curso de Engenharia Industrial, acrescentando que a pretensão, agora, é de transformar toda a estrutura numa espécie de 'Centrão' que integraria a Escola Técnica Federal da Bahia, o Centro Tecnológico e o Curso de Engenharia Industrial. Com isso, o Curso de Engenharia de Operações, de curta duração, evoluiria, segundo eles, para o Curso de Engenharia Industrial, de duração plena. (apud Lessa, s/data.Grifos nossos)

Na Bahia, este projeto do "Centrão" teria sido deixado de lado naquele momento; no entanto, vemos nele já a idéia do que, pouco mais tarde, em 1978, seriam os primeiros Centros Federais de Educação Tecnológica (CEFETs).

A Lei 6.545 , de 30 de junho de 1978, criou - a partir da transformação das Escolas Técnicas Federais de Minas Gerais, do Paraná e Celso Suckow da Fonseca - três Centros Federais de Educação Tecnológica, em vez dos seis "Centros de 


\section{frabalhonecessário}

issn: $1808-799 \mathrm{X}$

ano 7 - número 9 - 2009

Engenharia de Operação". Assim, esta lei foi considerada como tendo concretizado o que preconizava aquele Acordo entre o MEC e o Banco Mundial, de 1971, sob a responsabilidade do PRODEM. No acordo que vinha sendo tecido no âmbito do $M E C$, essa havia sido a fórmula encontrada para, dentre outros aspectos, convencer o PRODEM a apoiar a política do DAU de extinção da engenharia de operação. Se compararmos a Lei 6.545 com a Lei 6.344 (criação CENTEC-BA), verificaremos que são bastante semelhantes; a própria Exposição de Motivos daquela, afirma que "a estrutura administrativa de cada Centro [...] terá como paradigma a do Centro de Educação Tecnológica da Bahia, recentemente criado". No entanto, aos CEFETs como no projeto dos "Centrões" - caberia ministrar "ensino de $2^{\circ}$ grau técnico industrial' e, quanto ao ensino superior, além dos Cursos Superiores de Tecnologia e de formação de recursos humanos na área, caberia ministrar também os cursos de engenharia industrial. A novidade, em relação aos "Centrões", foi a definição dos CEFETs como instituições que também deveriam se dedicar à pós-graduação e à pesquisa na "área técnica industrial".

\section{4- Considerações finais: de formação profissional à "educação profissional e tecnológica"}

Defendemos que a definição da "área técnica industrial" - à qual a hoje 'Rede Federal de Educação Profissional, Científica e Tecnológica', ao longo de sua história, deveria se dedicar - nunca ficou bem clara. Substituída, em parte, pelas expressões "área tecnológica"21, "educação tecnológica", ou mesmo "educação profissional"- não apenas pelos documentos oficiais do Ministério da Educação e de suas Instituições, mas também por alguns estudiosos da formação profissional no país - não nos parece ter alcançado precisão. Ao contrário, o fato do termo "industrial" não ser mais tão freqüente amplia as possibilidades de uso das expressões, tornando a definição ainda mais imprecisa. Portanto, até hoje, mantém-se certa nebulosidade quanto a conceitos e práticas, possibilitando o uso de expressões como "educação profissional e tecnológica" com distintos significados. 


\section{trabalhonecessário}

issn: $1808-799 \mathrm{X}$

ano 7 - número 9 - 2009

Queremos aqui ressaltar a atual formalização - e prática - de uma estreita relação entre as expressões 'educação profissional' e 'educação tecnológica'.

Antes, porém, cabe notar que, quanto à 'educação tecnológica', os primeiros registros que observamos referem-se à criação do Centro de Educação Tecnológica da Bahia (CENTEC-BA), em 1976, e dos três primeiros Centros Federais de Educação Tecnológica (CEFETs), em 1978. Quanto à 'educação profissional', segundo Neves e Pronko (2008, p.60) é "de uso recente na nossa literatura educacional", tendo sido introduzida na LDB de 1996 como título do capítulo III e refletindo "a necessidade do capital de dar ao treinamento da força de trabalho um conteúdo distinto daquele adequado ao período fordista de organização do trabalho e da produção" (ibid.).

Apesar de serem formuladas em momentos com algumas especificidades históricas distintas, as duas expressões vão, cada vez mais, se (con)fundindo, tendo em comum um conjunto de idéias que levam à (re)construção de uma concepção ideológica para uma educação que já é, na prática, diferenciada de acordo com as classes sociais. Uma formação voltada para a atuação em um determinado posto de trabalho, de acordo com necessidades específicas do capital, mas com um invólucro de educação geral e igual para todos: a "educação profissional e tecnológica".

1 Texto revisto e ampliado, originalmente publicado na revista Tecnologia e Cultura, ano $9, n^{\circ} 11$ (jul./dez. 2007). Rio de Janeiro, Centro Federal de Educação Tecnológica Celso Suckow da Fonseca, 2008.

${ }^{2}$ Decreto 13.721, de 13 de agosto de 1919, do Presidente Epitácio Pessoa e Decreto Municipal 2.133, de 6 de setembro de 1919, do Prefeito do Distrito Federal (apud DIAS, 1980).

${ }^{3} \mathrm{Em}$ novembro de 1993, no âmbito do I Encontro Nacional de Educação Tecnológica para o Desenvolvimento (I EDUTEC), realizado no próprio CEFET-CSF/RJ, foi organizada - com nossa colaboração, como membro da equipe de trabalho do Projeto Memória Viva: Coordenação e Pesquisa - a Exposição O CEFET tem história. Após o Encontro, as fotos utilizadas nessa Exposição, com a ajuda da Coordenação de Educação Artística, foram emolduradas tornando-se uma exposição permanente sobre a história do CEFET. Algumas dessas fotos ilustram a afirmação sobre a "seção de trabalhos femininos" da Wenceslau Brás. 
issn: $1808-799 \mathrm{X}$

ano 7 - número 9 - 2009

${ }^{4}$ A Wenceslau Brás, assim como as outras escolas da rede federal, deveria, a cada mês, encaminhar um boletim onde constasse o que os alunos haviam produzido nas oficinas durante as aulas e a quantia arrecadada na venda destes objetos. Em geral, esta venda ocorria durante as exposições anuais ou outras que porventura fossem organizadas.

${ }^{5}$ Projeto apresentado à Câmara dos Deputados em 15 de agosto de 1927. A versão integral do projeto encontra-se publicada em Fonseca, 1986, v.1, p.273.

${ }^{5}$ Decreto 24.558 , de 03 de julho de 1934. É importante lembrar que neste ano tivemos também uma nova Constituição onde, pela primeira vez, a educação aparecia como uma obrigação do Estado, passando a União a ser responsável pela determinação de diretrizes educacionais nacionais.

O Ministério da Educação e Saúde Pública havia sido criado em 14 de novembro de 1930, pelo Decreto 19.042. Em 05 de janeiro de 1931, o regulamento desse Ministério, aprovado pelo Decreto 19.560, criara a 'Inspetoria de Ensino Profissional Técnico'. Esta era uma das sete Repartições do Ministério, que não estava subordinada imediatamente ao Ministro, mas sim à 'Diretoria Geral de Expediente'. Vale ressaltar que, na estrutura de 1931, o Ministério tinha quatro Departamentos, todos diretamente subordinados ao Ministro e, dentre eles, o 'Departamento Nacional de Ensino'.

${ }^{8}$ História do Ensino Industrial no Brasil, "editada originariamente na Escola Técnica Nacional. A obra, dividida em dois volumes, teve seu primeiro volume publicado em 1961 e o segundo em 1962" (Rodrigues, 2002). Aspecto importante ressaltado por Rodrigues (ibid.) é o fato de que nesta obra Celso Suckow reproduz uma série de documentos históricos que, não tivessem sido aí resgatados, provavelmente teriam se perdido. Nesse nosso texto utilizamos alguns destes documentos.

${ }^{9}$ Sobre o assunto ver, dentre outros, Brandão (2009), Nascimento (1986), Peterossi (1980), Soares (1983).

${ }^{10}$ Este modelo de curso, nos EUA, existe desde o século XIX, no entanto, sua marcante expansão deu-se somente a partir dos anos 1960-1970 (Ghisolfi, 2004, p.72).

11 A Fundação Ford, criada em 1936, com ações da Companhia Automobilística Ford, é uma instituição privada estadunidense que entende ela própria como "a resource for innovative people and institutions worldwide. Our goals for more than half a century have been to: Strengthen democratic values; Reduce poverty and injustice; Promote international cooperation; Advance human achievement' (Disponível em: <http://www.fordfound.org/about/mission>). Esta Fundação financia, dentre outros, projetos educacionais, incluindo bolsas nos EUA para estudantes dos países "em desenvolvimento". Leher (2004, p.3), através das declarações de um importante assessor de Kenedy, nos mostra como instituições privadas estadunidenses, como a Fundação Ford, têm um importante papel nessas ações de propaganda ideológica.

${ }_{12}$ Decreto 57.075, de 15 de outubro de 1965 (Apud Nascimento, 1986, p.41). Em seu artigo 1으, o decreto estabelecia que "Os cursos de engenharia de Operação [...] poderão ser ministrados, 'unicamente', em estabelecimentos de ensino superior de engenharia" (Grifo nosso).

${ }^{13}$ Não há como deixar de observar a data deste convênio (8 de outubro), que parece ter sido a solução para que a Fundação Ford levasse adiante seus planos apesar do decreto 57.075; esta data é anterior à do referido decreto, com uma antecedência de apenas poucos dias.

${ }^{14}$ Ver a esse respeito Nascimento (1986) e Soares (1983).

${ }^{15}$ Referimo-nos ao sistema CONFEA/CREAs, isto é, ao Conselho Federal de Engenharia, Arquitetura e Agronomia e aos Conselhos Regionais de Engenharia, Arquitetura e Agronomia.

${ }^{16}$ O Banco Mundial (World Bank Group) é constituído de cinco Instituições, dentre elas, o Banco Internacional para a Reconstrução e Desenvolvimento (BIRD). O BIRD, apesar de ser uma das Instituições do Banco Mundial, ficou, ele próprio, conhecido como Banco Mundial. Por isso, é muito comum que se encontre, em diferentes textos, referência ao BIRD como sendo o Banco Mundial como um todo. Em nosso caso, o financiamento na área educacional tem sido realizado pelo World Bank Group através do BIRD.

${ }^{17}$ Artigo $1^{\circ}$ do Decreto 68.681, de 25 de maio de 1971 (Apud Góes Filho, op.cit., p.60). 


\section{trabalnonecessário}

issn: $1808-799 \mathrm{X}$

ano 7 - número 9 - 2009

18 Em 1977, o CFE, através de resoluções, caracterizou a habilitação de engenharia industrial, revogou a criação dos cursos de engenharia de operação e estabeleceu as normas para conversão destes últimos em engenharia industrial. Respectivamente, Resoluções CFE 04/77, 5/77, e 5A/77.

${ }^{19}$ Este ethos, pelo menos em parte, prevaleceu até há pouco tempo nos cursos de engenharia industrial. Por exemplo, no sítio oficial do CEFET-CSF/RJ, encontramos a seguinte definição para os cursos de Engenharia Industrial oferecidos pela Instituição: "voltados para a formação de engenheiros que se dedicarão precipuamente ao desenvolvimento de processos industriais e à operação dos sistemas industriais. Mesmo que a formação básica desses engenheiros tenha a mesma extensão e profundidade das demais habilitações de engenharia, na Engenharia Industrial, 'o enfoque principal deve ser conferido ao trabalho prático e às técnicas e aos processos de operação que caracterizam a atividade industrial'." (Grifos nossos). Disponível em: <http://www.cefetri.br/concurso/graduacao/manualdoaluno/manual/cursosgraduacao.htm > Acesso em: 01 de agosto de 2006. Atualmente, ao digitarmos este endereço, obtivemos ainda as mesmas informações; no entanto, os cursos de. engenharia da Instituição passaram por um processo de reformulação e, para informações do que hoje se divulga formalmente (ementas de disciplinas e fluxogramas), deve-se acessar: http://www.cefet-ri.br/ensino/ensino2.htm. Acesso em 03 de agosto de 2008.

${ }^{20}$ Lei federal 6.344, de 6 de julho de 1976.

${ }^{21}$ A partir da Lei 6.545, de 1978, o CEFET-CSF/RJ - junto daqueles de Minas Gerais e Paraná passa a ser uma instituição diferenciada das ETFs. No entanto, apenas em 1993 (com a Lei 8.711, de 28 de setembro, que transforma a ETF-BA em CEFET-BA e dá outras providências), os CEFETs passam a poder ministrar, em grau superior, graduação visando à formação de profissionais e especialistas na 'área tecnológica' - e não apenas engenharia industrial e formação de tecnólogos.

\section{REFERÊNCIAS BIBLIOGRÁFICAS}

BRANDÃO, Marisa. Metamorfose dos Cursos Superiores de Tecnologia no Brasil: política de acesso ao ensino superior em um Estado burguês. Niterói: 2009. 248f. Tese (Doutorado em Educação) - Programa de Pós-Graduação em Educação, Universidade Federal Fluminense, Niterói. 2009.

Das artes e ofícios ao ensino industrial: continuidades, adaptações e rupturas na construção da identidade do CEFET-RJ. Niterói: 1997. 166f. Dissertação (Mestrado em Educação) - Programa de Pós-Graduação em Educação, Universidade Federal Fluminense, Niterói. 1997.

DIAS, Demósthenes de Oliveira. Estudo documentário e histórico sobre a Escola Técnica Federal 'Celso Suckow da Fonseca'. RJ: CEFET/RJ, 1980.

FONSECA, Celso Suckow da. História do ensino industrial no Brasil. Rio de Janeiro: SENAI, Vol.1 e Vol.3, 1986.

FRANCO, Maria Ciavatta, GONTIJO, Rebeca. Celso Suckow da Fonseca. In: FÁVERO, Maria de Lourdes de Albuquerque; BRITTO, Jader de Medeiros (Org.). Dicionário de Educadores no Brasil: da Colônia aos dias atuais. Rio de Janeiro: EdUFRJ, MEC-INEP, 2002 ( $2^{\mathrm{a}}$ ed.). p.253-258.

GHISOLFI, Juliana do Couto. Políticas de educação superior norte-americanas: faça o que digo mas não faça o que faço?. São Paulo: Cortez, 2004 (Coleção questões de nossa época, v.121). 


\section{trabalhonecessário}

issn: $1808-799 \mathrm{X}$

ano 7 - número 9 - 2009

GÓES FILHO, Joaquim Faria; Netto, Carolina Alice Coutinho (org.). Cursos Superiores de duração reduzida. Versão preliminar de relatório de pesquisa. Rio de Janeiro: FGV/IRH, MEC/INEP, Vol. I, 1976.

LEHER, Roberto. A new lord of education? World Bank policy for peripheral capitalism. Journal for Critical Education Policy Studies. Volume 2, number 1 (March 2004). Disponível em: <http://www.jceps.com/?pagelD=article\&articlelD=20>. Acesso em: $28 \mathrm{de}$ dezembro de 2008.

LESSA, José Silva. CEFET-BA - uma resenha histórica: da escola do mingau ao complexo integrado de educação tecnológica. Disponível em: <http://www.cefetba.br/comunicacao/resenha.html> Acesso em: 21 de jan. de 2007.

NASCIMENTO, Osvaldo. O ensino industrial no Brasil: 75 anos do ensino técnico ao ensino superior. RJ: SENAI/DN/DPEA, 1986.

NEVES, Lúcia Maria Wanderley; PRONKO, Marcela Alejandra. O mercado do conhecimento e o conhecimento para o mercado: da formação para o trabalho complexo no Brasil contemporâneo. Rio de Janeiro: EPSJV, 2008.

OLIVEIRA, Regina Rita de Cássia. Cursos Superiores de "curta duração" - esta não é uma conversa nova. Revista Educação Tecnológica. Belo Horizonte: v.8, n.2, p.18-25, jul./dez. 2003. Disponível em: <www.dppg.cefetmg.br/revistan8v2-artigo3.pdf>.

PETEROSSI, Helena Gemignani. Educação e mercado de trabalho: análise crítica dos cursos de tecnologia. SP: Edições Loyola, 1980.

RODRIGUES, José. Celso Suckow da Fonseca e a sua História do Ensino Industrial no Brasil. Revista Brasileira de História da Educação. Campinas: v. 2, n. 4, p. 47-74, 2002.

SOARES, Rose Mary Dore. Formação de técnicos de nível superior no Brasil: do engenheiro de operação ao tecnólogo. Belo Horizonte: 1983. 342f. Dissertação (Mestrado em Educação) - Faculdade de Educação, Universidade Federal de Minas Gerais, Belo Horizonte. 1983.

Dados da autora: Marisa Brandão. Doutora em Educação. Socióloga. Professora de Sociologia do Ensino Médio e Técnico do CEFET- Celso Suckow da Fonseca/RJ. 